\title{
Chlorophyll Formation in \\ Euglena gracilis var. bacillaris: Interference by Analogues of Purines, Pyrimidines and Amino Acids
}

\author{
By P. J. DUBASH AND D. V. REGE \\ Department of Chemical Technology, University of Bombay, \\ Matunga, Bombay 19, India \\ (Accepted for publication 16 March 1967)
}

SUMMARY

Chlorophyll formation in non-growing etiolated cells of Euglena gracilis var. bacillaris is inhibited by certain antimetabolite analogues of purines, pyrimidines and amino acids. The inhibitory effects of bromo- and nitrouracils were annulled by uracil and thymine; those of fluoro- and thio-uracils were not. Ethionine inhibition was completely annulled by methionine. All the base analogues were more inhibitory for the dark growth of the alga than in the light and an adaptation to these antimetabolites was apparent during growth. The growth inhibitory effects of some of these base analogues was annulled by several Krebs's cycle intermediates; the latter in themselves stimulated growth of photosynthesizing euglenas although they were not utilized in the dark with any degree of efficiency.

Long-term exposure of non-proliferating euglenas, green or etiolated, to 5-fluoro-uracil had a profound effect on the chloroplast integrity of the organisms. Such euglenas on further subculture in an adequate growth medium were permanently bleached. The effect of 5-bromo-uracil, though similar, was less marked.

\section{INTRODUCTION}

Euglena gracilis, a green photosynthetic flagellate, loses its chlorophylls when grown heterotrophically in the dark. Exposure of such colourless euglenas to light brings about the re-synthesis of chlorophyll accompanied by a considerable increase in chloroplast proteins and the RNA of several subcellular fractions (Brawerman \& Chargaff, 1959a; Brawerman, Pogo \& Chargaff, 1962). An additional RNA species associated with the chloroplasts and which is specifically formed during their induced formation in light was demonstrated by Pogo, Brawerman \& Chargaff (I962). These results suggest that light induces the associated synthesis of specific types of proteins concomitant with chlorophyll synthesis. The effect of certain antimetabolite analogues of purines, pyrimidines and amino acids was therefore tested to verify such an association.

Euglena gracilis is the only phytoflagellate which can be rendered permanently apochlorotic by an assortment of chemical agents, e.g. streptomycin (Provasoli, Hutner \& Schatz, 1948; Jírovec, 1949), antihistamines (Gross, Jahn \& Bernstein, 1955), $O$-methylthreonine (Aaronson \& Bensky, 1962), furadantin (McCalla, 1962), erythromycin (Ebringer, 1962) and magnesium starvation (Dubash \& Rege, 1967); and physical agents such as heat (Pringsheim \& Pringsheim, 1952; Brawerman \& 
Chargaff, 1959b) and ultraviolet radiation (Pringsheim, 1958). This phenomenon of permanent apochlorosis is one of the few instances of a cytoplasmic mutation, with a consequent alteration of phenotype, being induced by environmental changes. In E. gracilis var. bacillaris, diverse agents operating in unknown ways affect finally the synthesis of chlorophyll or plastid or both. The mechanism of action of any of such agents is not yet fully understood. 5-fluoro-uracil, which inhibits growth and chlorophyll synthesis in $E$. gracilis, has been found to render organisms of this alga permanently apochlorotic. Organisms grown in the dark with sulphanilamide and 5-bromouracil and subsequently plated on a basal medium were shown by Scher \& Collinge (I965) to be markedly mutated to the apochlorotic form, but although mere exposure to 5-fluoro-uracil can bring about a $100 \%$ mutation, we were not able to show a similar effect with 5-bromo-uracil even on longer exposures.

\section{METHODS}

Organisms of the photosynthetic strain of Euglena gracilis var. bacillaris were grown in the defined medium of Hutner, Provasoli, Schatz \& Haskins (1950) as described by Coelho \& Rege (1963); the medium for dark-grown cultures was supplemented with I \% glucose. Growth studies were made essentially by the method described earlier (Coelho \& Rege, 1963). For studies on chlorophyll synthesis by non-growing cultures under illumination, etiolated euglenas were obtained by growth in the dark for 7 days; these forms were harvested, washed twice with sterile distilled water under aseptic conditions and then suspended in a measured volume of sterile distilled water. Samples of this suspension were then dispensed in 6 in. $\times \frac{1}{2}$ in. rimless test tubes containing double- (or greater) strength of the 'resting' medium suggested by Brawerman \& Chargaff (1959a) composed of $1 \%$ glucose, $0.0 \mathrm{I} \mathrm{M}-\mathrm{KH}_{2} \mathrm{PO}_{4}$, and $0.0 \mathrm{I} \mathrm{M}-\mathrm{MgCl}_{2}$. $6 \mathrm{H}_{2} \mathrm{O}$ with additions where required. No rigorous sterility precautions needed to be observed as this medium did not favour bacterial growth. The euglenas were then illuminated with frequent shaking for $72 \mathrm{hr}$ at $28^{\circ}$ in a transparent glass tank by a pair of daylight fluorescent tubes placed io in. from the bottom of the tank.

Estimates of growth were made, after suitable dilution of cultures, by the method of Hutner, Bach \& Ross (1956), by measuring the turbidity with a Klett-Summerson photoelectric colorimeter with a $66(640-700 \mathrm{~m} \mu)$ filter. Photosynthetic pigments were routinely determined by extraction of euglenas with $3 \times 5^{\circ} 0 \mathrm{ml}$. methanol; these extracts were pooled, the volume made to $20 \mathrm{ml}$. with methanol and the colour intensity read with a Klett-Summerson colorimeter, using the same 66 filter. Absolute values, where given, were determined by the method described earlier (Dubash \& Rege, 1967).

Counts of euglenas were made in a Levy blood counting chamber after immobilizing the organisms by adding a drop of chloroform.

\section{RESULTS}

\section{Effect of antimetabolites on chlorophyll synthesis}

It was observed that all the analogues of uracil tried and 2,6-diamino-purine inhibited the synthesis of chlorophyll in suspensions of the euglena. Benzimidazole was without effect; 6-mercaptopurine showed a slight stimulation; ethionine, at higher concentration, was also inhibitory (Table I). The effects of 5-bromo- and 5-nitro- 
uracil were annulled by uracil and thymine; those of 5 -fluoro- and 5-thio-uracil were not (Table 2). The inhibition by ethionine was completely annulled by methionine. The incorporation of ethionine into the euglenas showed a lag period; short-term exposure to this analogue before illumination did not inhibit chlorophyll synthesis (Table 3).

Table I. Effect of analogues of purines, pyrimidines and amino acids on chlorophyll synthesis in resting etiolated Euglena gracilis var. bacillaris
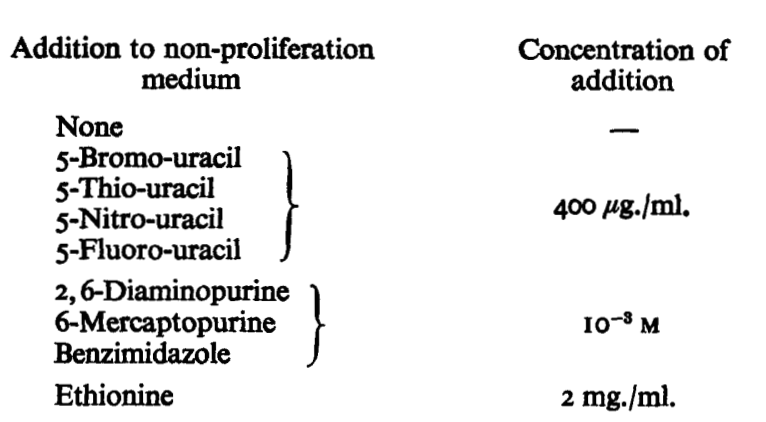
Inhibition of chlorophyll synthesis $(\%)$

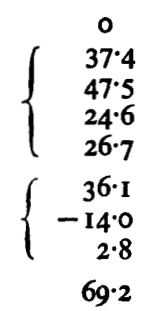

Table 2. Effect of uracil analogues on chlorophyll synthesis by etiolated Euglena gracilis var. bacillaris: annulment by uracil and thymine

\begin{tabular}{|c|c|c|c|}
\hline $\begin{array}{l}\text { Addition to non-proliferation } \\
\text { medium } \\
(400 \mu \mathrm{g} . / \mathrm{ml} .)\end{array}$ & $\begin{array}{l}\text { Net synthesis of } \\
\text { chlorophyll/mg. } \\
\text { dry wt euglenas*/ } \\
72 \mathrm{hr} \text { m } \mu \mathrm{g} .\end{array}$ & $\begin{array}{c}\text { Inhibition } \\
(\%)\end{array}$ & $\begin{array}{c}\text { Annulment } \\
(\%)\end{array}$ \\
\hline None & 1812 & - & - \\
\hline 5-Bromo-uracil (BU) & 1101 & $37 \cdot 4$ & 一 \\
\hline 5-Thio-uracil (TU) & 964 & $47 \cdot 5$ & - \\
\hline 5-Nitro-uracil (NU) & 1376 & $24 \cdot 6$ & - \\
\hline 5-Fluoro-uracil (FU) & 1330 & $26 \cdot 7$ & - \\
\hline Uracil (U) & 1796 & $I \cdot 0$ & - \\
\hline Thymine (Th) & I536 & 15.5 & - \\
\hline $\mathbf{B U}+\mathbf{U}$ & 1697 & 6.5 & $85 \cdot 0$ \\
\hline $\mathbf{B U}+\mathbf{T h}$ & 1468 & 19.0 & $49 \cdot 1$ \\
\hline $\mathbf{T U}+\mathbf{U}$ & 1009 & $44 \cdot 5$ & 6.4 \\
\hline $\mathrm{TU}+\mathrm{Th}$ & 917 & $49 \cdot 5$ & $-4 \cdot 2$ \\
\hline $\mathrm{NU}+\mathrm{U}$ & 1812 & 0 & 100 \\
\hline $\mathrm{NU}+\mathrm{Th}$ & 1514 & I6.6 & $32 \cdot 6$ \\
\hline $\mathbf{F U}+\mathbf{U}$ & 1399 & $23 \cdot 0$ & 13.9 \\
\hline $\mathbf{F U}+\mathbf{T h}$ & 1005 & $44 \cdot 5$ & -66.5 \\
\hline
\end{tabular}

* Dry weights of euglenas were calculated from counts according to the relationship suggested by Kirk (1962).

Effect of antimetabolites on the growth of Euglena gracilis var. bacillaris

In view of the effect of these various antimetabolite analogues on chlorophyll synthesis in non-proliferation conditions, their influence on growth was studied. To verify whether the effect on growth was due only to interference with chlorophyll biosynthesis, the studies were extended to dark-grown cultures as well. Table 4 shows that all purine and pyrimidine analogues tested were more inhibitory in the dark than in the light. The organism thus appeared to use pathways for carbohydrate metabolism which were 
different in the heterotrophic and photosynthetic phases. The possibility of light instability of some of the compounds cannot, however, be precluded. Whether such an action indicates that these analogues might hamper in some way the utilization of glucose as a source of energy was examined by experiments designed to test the effects of various breakdown products of glucose and the Krebs cycle intermediates in the presence of these antimetabolites. Table 5 shows the effect of the Krebs cycle intermediates on the growth of Euglena in the presence and absence of 8-azaguanine. The

Table 3. Effect of ethionine on chlorophyll synthesis in non-proliferating etiolated Euglena gracilis var. bacillaris organisms: annulment by methionine

Euglenas were grown heterotrophically in the dark for 7 days, harvested, washed and resuspended in water. Equal samples were used for the different treatments. Illumination was for $96 \mathrm{hr}$; the chlorophylls were extracted with methanol as described in the text. Klett readings were taken with the 66 filter. Pre-exposure was effected by suspending the etiolated euglenas in non-proliferation medium containing the additions at $2 \mathrm{mg}$. $/ \mathrm{ml}$; the same concentration was used during illumination.

Treatment

I. Blank

2. Non-proliferation medium + ethionine

3. Euglenas exposed to ethionine for $15 \mathrm{~min}$., washed and taken up in non-proliferation medium

Chlorophyll

index Inhibition Annulment

(Klett units) $\quad(\%) \quad(\%)$

Euglenas exposed to ethionine for $15 \mathrm{~min}$., centrifuged and taken up in non-proliferation medium without washing

5. Non-proliferation medium + ethionine + methionine

6. Euglenas exposed to ethionine + methionine for $15 \mathrm{~min}$., washed and taken up in non-proliferation medium

7. Euglenas exposed to ethionine + methionine for $15 \mathrm{~min}$., centrifuged and taken up in non-proliferation medium without washing

8. Euglenas exposed first to ethionine for $15 \mathrm{~min}$., then to methionine for $15 \mathrm{~min}$., washed and taken up in non-proliferation medium

$\begin{array}{rrr}162 & - & - \\ 50 & 69 \cdot 2 & - \\ 161 & 0 & - \\ & & \\ 93 & 42 \cdot 5 & 100 \\ 161 & 0 & - \\ 165 & 0 & \\ & & \\ 165 & 0 & - \\ 165 & 0 & - \\ 167 & 0 & \\ 167 & 0 & \end{array}$

9. Euglenas exposed to ethionine for $15 \mathrm{~min}$., washed and taken up in non-proliferation medium containing methionine

I0. Non-proliferation medium + methionine

Table 4. Effect of purine and pyrimidine antimetabolite analogues on the light and dark growth of Euglena gracilis var. bacillaris

\begin{tabular}{lccc} 
Analogue added & $\begin{array}{c}\text { Concentration } \\
\left(\times 10^{3}-M\right)\end{array}$ & Light & Dark \\
\cline { 3 - 4 } None & - & 0 & 0 \\
5-Bromo-uracil & $1 \cdot 048$ & $4 \cdot 0$ & 43.6 \\
5-Thio-uracil & $1 \cdot 560$ & $2 \cdot 8$ & $8 \cdot 5$ \\
5-Nitro-uracil & $1 \cdot 272$ & $4 \cdot 4$ & 5.6 \\
5-Fluoro-uracil & $1 \cdot 526$ & $97 \cdot 9$ & 100 \\
& 0.153 & $27 \cdot 2$ & $71 \cdot 1$ \\
8-Azaguanine & $1 \cdot 314$ & 19.4 & 53.5 \\
8-Azaxanthine & $1 \cdot 304$ & 0 & 5.0 \\
8-Azaadenine & $1 \cdot 470$ & 19.4 & 49.3
\end{tabular}


inhibition due to 8-azaguanine was less evident in the dark in the presence of lactate or $\alpha$-ketoglutarate and was completely overcome by citrate, although these compounds cannot replace glucose in the medium with growth stimulatory action. In the light, 8-azaguanine was completely ineffective in the presence of $\alpha$-ketoglutarate and citrate. It was further observed that many of the carbon compounds stimulated growth of the organism in the light although some of these could not be utilized in the dark.

Table 5. Effect of Krebs cycle intermediates on the 8-azaguanine inhibition of growth of Euglena gracilis var. bacillaris

\begin{tabular}{|c|c|c|c|c|c|c|}
\hline \multirow{4}{*}{$\begin{array}{l}\text { Krebs cycle acid added* } \\
\text { (1 \%) }\end{array}$} & \multicolumn{6}{|c|}{ Growth (Klett units at $660 \mathrm{~m} \mu$ ) } \\
\hline & \multirow{2}{*}{\multicolumn{2}{|c|}{ Without 8-azaguanine }} & \multicolumn{4}{|c|}{ With 8-azaguanine } \\
\hline & & & & Inhibition & & Inhibition \\
\hline & Dark & Light & Dark & $(\%)$ & Light & $(\%)$ \\
\hline None & 79 & 286 & 42 & $46 \cdot 9$ & 264 & $7 \cdot 6$ \\
\hline Glucose & 298 & 422 & 142 & $52 \cdot 4$ & 345 & $18 \cdot 4$ \\
\hline Pyruvate & 48 & 126 & 23 & $52 \cdot 0$ & 114 & $9 \cdot 5$ \\
\hline Lactate & 85 & 350 & 70 & $17 \cdot 6$ & 305 & $13 \cdot 0$ \\
\hline Succinate & 115 & 422 & 53 & $54 \cdot 0$ & 252 & $40 \cdot 3$ \\
\hline Malate & 95 & 422 & 48 & $49 \cdot 5$ & 320 & $24 \cdot I$ \\
\hline$\alpha$-Ketoglutarate & 27 & 194 & 22 & 18.6 & 208 & $-7 \cdot 0$ \\
\hline$\beta$-Glycerophosphate & 54 & 211 & 36 & 33.4 & 100 & $52 \cdot 6$ \\
\hline Fumarate & 168 & 350 & 76 & $54 \cdot 7$ & 234 & $33 \cdot I$ \\
\hline Citrate & 65 & 325 & 64 & 0 & 348 & -7.0 \\
\hline
\end{tabular}

* Additions of Krebs intermediates were to the basal medium containing glutamate (1 \%) and malate $(0.2 \%)$, but without glucose.

\section{Adaptation to the presence of antimetabolites}

When euglenas grown in presence of 8-azaguanine were used to study their chlorophyll-synthesizing capacity, it was observed that 8-azaguanine was not as inhibitory to the synthesis of chlorophyll as it was to euglenas grown in absence of this analogue. Tables 6 and 7 show that not only were the analogues ineffective in most of the cases tried, but 8-azaderivatives of guanine and xanthine, and $S$-methylcysteine actually stimulated the synthesis of chlorophyll when euglenas grown in the dark in the presence of the antimetabolite analogue were illuminated in a non-proliferation medium in the continued presence of the same (Table 6). The effect of 5-bromo-uracil addition to the growth medium in the dark was to enhance synthesis of chlorophyll when etiolated euglenas were illuminated in a non-proliferation medium with or without this analogue; 5-bromo-uracil, however, inhibited chlorophyll synthesis in normal etiolated euglenas (Table I). With 5-nitro-uracil, with 8-azaderivatives of guanine and xanthine, and with $S$-methylcysteine there was only an increase in chlorophyll synthesis when the illumination in non-proliferation medium was also continued in the presence of the inhibitor. It was thought that this effect may have been due to some sort of adaptation of the euglenas to the inhibitor during the growth phase. After 7 days' growth in the dark in the presence of inhibitor a second transfer in the same medium brought about a decrease in the degree of inhibition in the case of 8-azaxanthine and $S$-methylcysteine, whereas the inhibition was increased in the case of 8-azaguanine. These results are given in Table 7. 
Table 6. Effect of continued presence of purine and pyrimidine antimetabolite analogues on chlorophyll synthesis in non-proliferating etiolated organisms of Euglena gracilis var. bacillaris grown in the presence of the analogue: adaptation to certain analogues

\begin{tabular}{|c|c|c|c|c|}
\hline \multirow[b]{2}{*}{ Analogue } & \multirow{2}{*}{$\begin{array}{l}\text { Concentration in } \\
\text { the growth and } \\
\text { non-proliferation } \\
\text { medium } \\
\left(\times 10^{-8} \mathrm{M}\right)\end{array}$} & \multirow{2}{*}{$\begin{array}{l}\text { Dark } \\
\text { Growth } \\
\text { (Klett) }\end{array}$} & \multicolumn{2}{|c|}{$\begin{array}{l}\% \text { Chlorophyll synthesized pe } \\
\text { euglena in } 72 \mathrm{hr} \text { in non- } \\
\text { proliferation medium }\end{array}$} \\
\hline & & & Alone & +Analogue \\
\hline None & - & 142 & 100 & 100 \\
\hline 5-Bromo-uracil & $1 \cdot 048$ & 80 & I $28 \cdot I$ & $126 \cdot 0$ \\
\hline 5-Thio-uracil & $1 \cdot 560$ & 130 & $78 \cdot 3$ & $77 \cdot 0$ \\
\hline 5-Nitro-uracil & $1 \cdot 272$ & 134 & 65.8 & $72 \cdot 0$ \\
\hline 5-Fluoro-uracil & $I \cdot 526$ & 0 & 0 & 0 \\
\hline 8-Azaguanine & $1 \cdot 314$ & 66 & $96 \cdot 0$ & 129.5 \\
\hline 8-Azaxanthine & $1 \cdot 304$ & 135 & $72 \cdot 8$ & $85 \cdot 5$ \\
\hline 8-Azaadenine & $1 \cdot 470$ & 72 & $9 I \cdot 3$ & $78 \cdot 3$ \\
\hline$S$-Methylcysteine & $1 \cdot 480$ & 124 & $77 \cdot 3$ & $90 \cdot 4$ \\
\hline
\end{tabular}

Table 7. Effect of continued presence of antimetabolite growth inhibitors on the growth of Euglena gracilis var. bacillaris

Dark-grown euglenas in presence of the inhibitor were diluted to the same cell count and used as inocula for growth in presence or absence of the inhibitor as indicated.

Growth studies were done in the dark on a glucose-supplemented growth medium for 7 days.

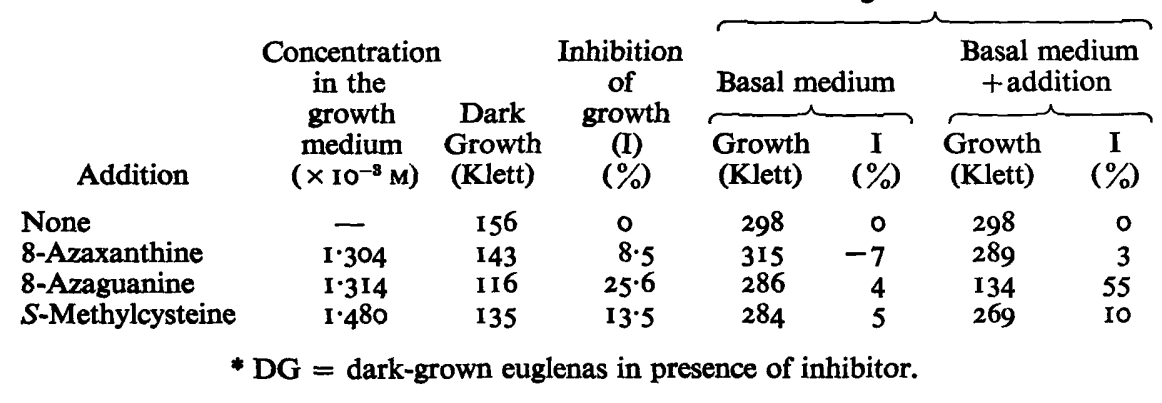

\section{Mutagenic effect of prolonged exposure to antimetabolite analogues of certain bases}

Scher \& Collinge (1965) demonstrated that 5-bromo-uracil gets incorporated into the euglenas during chloroplast replication leading to mutagenic changes and giving rise to bleached colonies. The effect of 5-fluoro- and 5-bromo- analogues of uracil was studied on non-proliferating suspensions of Euglena in the light. Long exposures to these base analogues brought about certain mutagenic changes in Euglena as evinced when these organisms were subcultured in a glucose-supplemented basal medium in the light. Exposure of green or etiolated euglenas for $144 \mathrm{hr}$ to 5-fluorouracil gave pure white cultures when a small population of the euglenas undergoing treatment was inoculated into a glucose-containing growth medium; these cultures were $100 \%$ bleached. The same effect was also observed with 5-bromo-uracil, but the bleaching was not $100 \%$. The 5-fluoro-uracil treated cultures were permanently bleached and never regained even a part of their chlorophyll when subsequently grown 
in the light for many transfers. On the other hand, 5-bromo-uracil-treated cultures, or cultures treated with 5-fluoro-uracil for less than $144 \mathrm{hr}$ were not completely or permanently bleached and returned to the original green state gradually after the analogue was withheld from the growth medium. The results of this experiment are summarized in Table 8.

Table 8. Effect of 5-fluoro-uracil and 5-bromo-uracil on non-proliferating Euglena gracilis var. bacillaris: loss of the photosynthetic apparatus on prolonged exposure to 5-fluorouracil

The euglena populations were exposed to the base antimetabolite analogues during the non-proliferation period whereafter 2 drops of a $1 / 50$ diluted euglena suspension was used as inoculum.

Colour of cultures after 7-day growth in light.

Type of euglenas suspended in non-proliferation medium

Dark-grown etiolated

\section{Addition to non-proliferation medium}

None

5-Fluoro-uracil

5-Bromo-uracil

None

5-Fluoro-uracil

5-Bromo-uracil
Concentra- Time of exposure to light (hr)*

\begin{tabular}{|c|c|c|c|c|}
\hline $\begin{array}{c}\text { addition } \\
\text { (mg. } \% \text { ) }\end{array}$ & 0 & & $\begin{array}{c}72 \\
1 r^{\dagger}\end{array}$ & I 44 \\
\hline - & $\mathbf{G}$ & $\mathbf{G}$ & $\mathbf{G}$ & LG \\
\hline $\begin{array}{r}200 \\
50\end{array}$ & $\begin{array}{l}\mathbf{G} \\
\mathbf{G}\end{array}$ & $\begin{array}{l}\mathbf{G} \\
\mathbf{G}\end{array}$ & $\begin{array}{l}\mathbf{G} \\
\mathbf{G}\end{array}$ & $\underset{\mathbf{W}}{\mathbf{W}}$ \\
\hline $\begin{array}{r}200 \\
50\end{array}$ & $\begin{array}{l}\mathbf{G} \\
\mathbf{G}\end{array}$ & $\begin{array}{l}\mathbf{G} \\
\mathbf{G}\end{array}$ & $\begin{array}{l}\mathbf{G} \\
\mathbf{G}\end{array}$ & $\begin{array}{l}\text { LG } \\
\text { LG }\end{array}$ \\
\hline
\end{tabular}

$-\quad$ G $\quad$ G $\quad$ G $\quad$ LG

200 G $\quad G \quad$ G $\quad W$

$\begin{array}{lllll}50 & G & G & G & \text { W }\end{array}$

$\begin{array}{rllll}200 & \text { G } & \text { G } & \text { G } & \text { PY } \\ 50 & \text { G } & \text { G } & \text { G } & \text { PY }\end{array}$

* Time of exposure to analogue in the light in non-proliferation medium before transferring a $1 / 50$ diluted inoculum to a glucose-supplemented growth medium.

† $\mathbf{G}=$ green; $\mathbf{L G}=$ light green; $\mathbf{P Y}=$ pale yellow; $\mathbf{W}=$ white.

\$ White cultures permanently bleached.

\section{DISCUSSION}

Lyman, Epstein \& Schiff (196I) suggested the implication of self-reproducing cytoplasmic nucleoproteins during the formation of chloroplasts in Euglena gracilis. Ultraviolet radiation prevents the transmission of the chloroplasts of Euglena to their progeny; the process, which shows peaks of effectiveness at 260 and $280 \mathrm{~m} \mu$, can be photo-reactivated and these cytoplasmic entities are replicated at division and control the formation of chloroplasts (Schiff, Lyman \& Epstein, 1961). This cytoplasmic factor was thought to be DNA (Leff, Mandel, Epstein \& Schiff, 1963); subsequent work has definitely established the presence of chloroplastic DNA in Euglena (Edelman, Cowan, Epstein \& Schiff, 1964; Brawerman \& Eisenstadt, I96I ; Ray \& Hanawalt, 1964, 1965: Edelman, Schiff \& Epstein, 1965; Ray, 1965). The inhibition of chlorophyll synthesis in resting Euglena by actinomycin-D suggests a DNA-dependant synthesis of RNA during chloroplast development (McCalla \& Allan, I964).

The inhibition of chlorophyll synthesis by 5-bromo-uracil and its annulment by uracil or thymine shows that there is possibly a de novo synthesis of nucleoproteins 
occurring during the development of chloroplasts in resting etiolated euglenas and this in some manner is closely associated with the synthesis of chlorophyll. These nucleoproteins are presumably involved in the synthesis of specific proteins: either the enzymes required for photosynthesis, and/or the protein involved in the chlorophyllprotein complex. The inhibition of greening by ethionine and its annulment by methionine also shows that such proteins are possibly being formed de novo during illumination of dark-grown organisms. However, according to Gibson, Neuberger \& Tait (1962 b), the inhibition of chlorophyll synthesis by ethionine, in Rhodopseudomonas spheroides, is likely to be due to inhibition by competition with methionine of the formation of the methyl ester group of chlorophyll. The formation of NADP-requiring glyceraldehyde-3-phosphate dehydrogenase during chloroplast formation was shown by Fuller \& Gibbs (1959) and Brawerman \& Konigsberg (1960). This enzyme is characterized by its absence from dark-grown colourless euglenas and its synthesis is blocked by any agent, chemical or physical, which blocks chloroplast formation. The de novo synthesis of the protein involved in the chlorophyll-protein complex is also suggested since any blockage in the synthesis of this protein, as with ethionine, would prevent chlorophyll formation simply because the chlorophyll would have no protein to which to attach. A similar mechanism of inhibition by streptomycin was suggested by Kirk (1962). The breakdown of existing proteins and peptides to amino acids which are then utilized for synthesis of chloroplast protein was also suggested by Kirk (1962) in contrast to a hypothesis suggested by Brawerman \& Chargaff (1959a) that there was an actual transfer of intact proteins from the soluble fraction to the chloroplast fraction. Gibson et al. (1962a,b) suggested that the porphyrin excretion by Rhodopseudomonas spheroides in the presence of ethionine was due to its interference with the utilization or synthesis of methionine.

All the antimetabolite analogues of bases tested here were more inhibitory to the growth of Euglena gracilis var. bacillaris in the dark than in the light. This suggests that the observed effect on growth was due more likely to the inability of the euglenas to utilize glucose rather than to their ability to photosynthesize it. It is apparent that the metabolic pattern of the organisms is markedly influenced by the mode of life, photosynthetic or otherwise. How far the stability of the antimetabolite compounds, or the permeability of the euglenas to these is affected in light is not known. In the light, ATP is generated by the process of photosynthetic phosphorylation and the organisms do not require to metabolize glucose to derive energy. In the dark, where ATP formation depends entirely on glucose utilization, this inhibition is more pronounced. The dark-inhibition by 8 -azaguanine ws overcome to some extent by certain Krebs's cycle intermediates like lactate and $\alpha$-ketoglutarate and completely by citrate. During the formation of chloroplasts by non-proliferating etiolated Euglena gracilis organisms, the chlorophyll-less euglenas in the initial stages have to rely on exogenous glucose as sole source of ATP until such time as they synthesize enough chlorophyll to derive energy from other pathways such as photosynthetic phosphorylation.

The work of Scher \& Collinge (1965) which suggested the incorporation of 5-bromouracil into the plastid material during chloroplast replication provides another explanation to the mode of inhibition of greening by these base analogues. That such an incorporation takes place is manifested by the formation of bleached colonies, indicating mutagenesis. 5-Fluoro-uracil-treated euglenas also give rise to bleached cultures, although 5-fluoro-uracil does not totally inhibit the greening of resting etio- 
lated euglenas at a concentration at which this analogue exerts a permanent bleaching effect on cultures derived even from green euglenas. This suggests that the site of action of 5-fluoro-uracil is at a stage before the accumulation of the 'dark-precursor' of chlorophyll. It is, however, not clear whether 5-fluoro-uracil interferes with the formation or functioning of the chloroplastic satellite DNA of Euglena or produces drastic metabolic changes by affecting the nuclear DNA. 5-Fluoro-uracil is known to inhibit DNA synthesis by being converted to the deoxyribotide which is a potent inhibitor of thymidylate synthetase activity (Heidelberger, 1963). Thymidine has been shown to annul the inhibition of growth of Escherichia coli by 5-fluoro-uracil (Mankodi, 1964). 5-Fluoro-uracil is also known to be incorporated into RNA, rendering it inefficient in directing normal protein synthesis (Nakada \& Magasanik, 1964). 5Bromo-uracil had a similar effect, though less pronounced with Euglena gracilis var. bacillaris, and further exposures up to $312 \mathrm{hr}$ failed to bring about complete bleaching. The 5-fluoro-uracil bleaching of Euglena is analogous to the bleaching effects previously observed by exposures to streptomycin (Provasoli et al. 1948; Jírovec,1949; Provasoli, Hutner \& Pintner, I95I), antihistamines (Zahalsky, Hutner, Keane \& Burger, 1962), furadantin (McCalla 1962), $O$-methylthreonine (Aaronson \& Bensky, 1962), erythromycin (Ebringer, 1962), heat (Brawerman \& Chargaff, 1959b), short-term ultraviolet radiation (Lyman et al. 196I ; Schiff et al. 196I), and $\mathrm{Mg}^{2+}$ starvation (Dubash \& Rege, 1967). Although the site of action of each of these mutagens may be different, in all these cases the permanent loss of photosynthetic ability is preceded by a reversible lesion.

Evidence has been presented for the operation of the Krebs cycle in Euglena by Danforth (1953); the reversal of 8-azaguanine inhibition by several Krebs intermediates, both in light as well as in dark, indicates the involvement of this cycle. However, the organism appears to employ pathways for carbohydrate metabolism which are fundamentally different in the dark and photosynthetic phases. A possibility of greater turnover of nucleic acids during the dark adaptive phase is also indicated. The increased formation of chlorophyll on the continued presence of the analogues during chloroplast formation after the cells are first grown in the dark in the presence of the analogue indicates a degree of adaptation of the cells during the growth phase towards the inhibitor.

\section{REFERENCES}

AARONSON, S. \& BensKy, B. (1962). O-Methylthreonine, a new bleaching agent for Euglena gracilis. J. gen. Microbiol. 27, 75.

Brawerman, G. \& Chargaff, E. (I959a). Changes in protein and ribonucleic acid during the formation of chloroplasts in Euglena gracilis. Biochim. biophys. Acta 3r, 164.

Brawerman, G. \& Chargaff, E. (1959b). Factors involved in the development of chloroplasts in Euglena gracilis. Biochim. biophys. Acta 31, 178.

Brawerman, G. \& Eisenstadt, J. M. (1964). Deoxyribonucleic acid from the chloroplasts of Euglena gracilis. Biochim. biophys. Acta 91, 477.

BraWERman, G. \& KonigsberG, N. (1960). On the formation of the TPN requiring glyceraldehyde3-phosphate dehydrogenase during the production of chloroplasts in Euglena gracilis. Biochim. biophys. Acta 43, 374.

Brawerman, G., Pogo, A. O. \& Chargaff, E. (1962). Induced formation of ribonucleic acids and plastid protein in Euglena gracilis under the influence of light. Biochim. biophys. Acta 55, 326.

Coelho, J. \& Rege, D. V. (1963). On hemoglobin inhibition of the growth of Euglena gracilis. J. Protozool. 10, 473.

DANForth, W. F. (1953). Oxidative metabolism of Euglena. Arch. Biochem. 46, I64.

Dubash, P. J. \& Rege, D. V. (1967). Permanent bleaching of Euglena by $\mathbf{M g}^{2+}$ starvation. Biochim. biophys. Acta r36, 185. 
EBRINGER, L. (1962). Erythromycin induced bleaching of Euglena gracilis. J. Protozool. 9, 373.

Edelman, M., Cowan, C. A., Epstein, H. T. \& Schiff, J. A. (1964). Chloroplast development in Euglena. VIII. Chloroplast associated DNA. Proc. natn. Acad. Sci., U.S.A. 52, 214.

Edelman, M., Schiff, J. A. \& Epstein, H. T. (1965). Chloroplast development in Euglena. XII. Two types of satellite DNA. J. molec. Biol. II, 769 .

FulleR, R. C. \& GiBBs, M. (1959). Intracellular and phylogenetic distribution of ribulose I, 5diphosphate carboxylase and d-glyceraldehyde-3-phosphate dehydrogenase. Plant Physiol. 34, 324.

Gibson, K. D., Neuberger, A. \& TAIT, G. H. (1962a). Studies on the biosynthesis of porphyrin and bacteriochlorophyll by Rhodopseudomonas spheroides. Biochem. J. 83, 539.

Gibson, K. D., NeuBerger, A. \& TATT, G. H. $(1962 b)$. Studies on the biosynthesis of porphyrin and bacteriochlorophyll by $R$. spheroides. 2. The effects of ethionine and threonine. Biochem. $J$. 83,550 .

Gross, J. A., JAHN, T. L. \& Bernstein, E. (1955). The effect of antihistamines on the pigments of green protista. J. Protozool. 2, 71.

HeIDELBerger, C. (1963). Biochemical mechanisms of action of fluorinated pyrimidines. Exp. cell Res. Suppl. 9, 462.

HUtNeR, S. H., BACH, M. K. \& Ross, G. I. M. (1956). A sugar-containing basal medium for vitamin $\mathrm{B}_{12}$-assay with Euglena: application to body fluids. J. Protozool. 3, IoI.

Hutner, S. H., Provasoli, L., Schatz, A. \& Haskins, C. (1950). Some approaches to the study of the role of metals in the metabolism of micro-organisms. Proc. Am. Phil. Soc. 94, 152.

Jf́Rovec, O. (1949). Úěinek antibiotik na některé prvoky. Mém. Soc. zool. tchécosl. 13, 216.

KIRK, J. T. O. (1962). Effect of streptomycin on greening and biosynthesis in Euglena gracilis. Biochim. biophys. Acta 56, 139.

LefF, J., MANDel, M., Epstein, H. T. \& SchifF, J. A. (1963). DNA satellites from cells of green and aplastidic algae. Biochem. biophys. Res. Communs. 13, 126.

Lyman, H., Epstein, H. T. \& Schirf, J. A. (196I). Studies of chloroplast development in Euglena. I. Inactivation of green colony formation by u.v.-light. Biochim. biophys. Acta 50, $30 \mathrm{I}$.

Mankodi, B. S. (1964). Studies in nucleotide metabolism in micro-organisms. Ph.D. (Tech.) Thesis, University of Bombay.

McCalla, D. R. (1962). Chloroplasts of Euglena gracilis affected by furadantin. Science 137, 225.

MCCALLA, D. R. \& AlLAN, R. K. (1964). Effect of actinomycin D on Euglena chloroplast formation. Nature, Lond. 201, 504.

NAKADA, D. \& MAGASANIK, B. (1964). The roles of inducer and catabolite repressor in the synthesis of $\beta$-galactosidase by Escherichia coli. J. molec. Biol. 8, ro5.

Pogo, A. O., Brawerman, G. \& Chargaff, E. (1962). New ribonucleic acid species associated with the formation of the photosynthetic apparatus in Euglena gracilis. Biochemistry I, I28.

Provasoli, L., Hutner, S. H. \& PintNer, I. J. (I95I). Destruction of chloroplasts by streptomycin. Cold Spr. Harb. Symp. quant. Biol. 16, I 13.

Provasoli, L., Hutner, S. H. \& Schatz, A. (1948). Streptomycin-induced chlorophyll-less races of Euglena. Proc. Soc. exp. Biol. Med. 69, 279.

Pringsheim, E. G. (1958). Die Apoplastidie bei Euglena. Rev. Algol. 4, 4I.

Pringsheim, E. G. \& Pringsherm, O. (1952). Experimental elimination of chromatophores and eyespot in Euglena gracilis. New Phytol. 5x, 65.

RAY, D. S. (1965). Isolation and physical characterization of the principal and satellite DNAs of Euglena gracilis. Disser. Abstr. 25, 6205.

Ray, D. S. \& Hanawalt, P. C. (1964). Properties of the satellite DNA associated with the chloroplasts of Euglena gracilis. J. molec. Biol. 9, 81 2.

Ray, D. S. \& HaNawalt, P. C. (1965). Satellite DNA components in Euglena gracilis cells lacking chloroplasts. J. molec. Biol. II, 760.

SCHER, S. \& COLIINGE, J. C. (1965). Chloroplast replication: Evidence for 5-bromo-uracil incorporation and plastid mutation in Euglena gracilis. Nature, Lond. 205, 828.

Schiff, J. A., Lyman, H. \& Epstein, H. T. (196I). Studies of chloroplast development in Euglena. II. Photoreversal of the UV inhibition of green colony formation. Biochim. biophys. Acta 5o, 310.

Zahalsky, A. C., Hutner, S. H., Keane, M. \& Burger, R. M. (1962). Bleaching Euglena gracilis with antihistamines and streptomycin-type antibiotics. Arch. Mikrobiol. 42, 46. 